\title{
'More is Better' as a Challenge to Sustainable Development: Theoretical and Empirical Approach
}

\author{
Prof. Dr. Sc. Tjaša Redek \\ Faculty of Economics, University of Ljubljana, Slovenia \\ E-mail: tjasa.redek@ef.uni-l].si \\ Dr.Sc. Anita Frajman Ivković \\ Faculty of Economics, University of J.J. Strossmayer in Osijek, Croatia \\ E-mail: afrajman@efos.hr
}

Doi:10.5901/mjss.2013.v4n2p11

\begin{abstract}
:
In 1987 the Brundtland commission introduced the idea of sustainable development, which is defined as environmentally friendly, more socially acceptable (equality) economic growth and development. There are three major components of sustainable development: environmental, economic and social. The research shows that fundamental societal reorientation in all three areas can lead to the successful sustainable development. The aim of the article is to examine the role of consumption for the implementation of sustainable development within a growth and development model. Sustainable development depends on the existence of a specific (not standard, consumption maximizing) consumer. The article develops the model of a new, environmentally oriented consumer, and takes account of the environmental component, as a contingency part of the consumer values. Then the new type is entered into a growth mode and the consequences for the implementation of sustainable development are examined. It is shown that consumers are social agents capable of changing their utility (well-being) maximization patterns and their attitude towards relative importance of different factors. Thereby consumers impact their consumption habits, but also give an important signal to the market and producers. Empirically, the model is illustrated by the attitudes of Slovenian consumers.
\end{abstract}

Key words: sustainable development, consumption, economic growth, environmentally oriented consumer

\section{Introduction}

Brundtland report (1987) introduced the concept of sustainable development resulting from two decades of observed changes in the global economy, especially the more obvious climate change and world poverty. The report defined sustainable development as a form of development which "meets the needs of the present without compromising the ability of future generations to meet their own needs". According to UNESCO (2010) sustainable development can also be called "the triple bottom line" of economic, social, and ecological sustainability.

One of the three elements the report focuses on is also the environmental dimension. Climate change has been an overriding theme in academic, political, business community and general public. Global warming unfortunately seems to be a big problem. According to NASA GISS Surface Temperature Analysis (2007) the period after 2000 is the warmest after 1880, with 2005 being the warmest year in recorded history. The consequences of global warming will be 'uncomfortable' and will change the natural environement, human health and economic welfare across the globe. Thus fighting against climate change must become one of the main elements of our daily life.

The aim of this article is to examine the consequences of a changed model of individual, primarily consumer on the economic growth in economy. Why? In order for the society to be able to indeed move towards a sustainable development model, it's consumers must change their values and embrace also the concepts related to sustainability and begin to behave socially responsible. In order to examine this, we developed a simple model of endogenous growth in which the consumers' preferences can depend on broader aspirations rather than just sole consumption utility and examined the consequences of such formulation on the economic growth. In addition, we illustrate the model with the attitudes of Slovenian consumers and evaluate thus the ability of Slovenia to implement the sustainable development 
model. The focus of the article will be on the environmental change, although the logic can easily be extended to all components of sustainability.

The structure of the article is as follows. In order to motivate the need to think about the changed pattern of consumption, first, we briefly described the main characteristics linked to the climate change, followed by the discussion on sustainability. Then, we focused on the consumer and placed him in the centre of the path towards sustainability, first by reviewing the theory linked to the role of the consumer in developing a sustainable economy and followed by a model of growth with a consumer with environmental aspirations, illustrating the results with Slovenian data. We concluded with a brief discussion on future extensions of this research ${ }^{1}$.

\section{Environmental change and the concept of sustainable development}

Twelve of the last thirteen years have been ranked among the warmest years since the beginning of the global temperature analysis. NASA Goddard Institute for Space Studies estimated in their article NASA Research Finds 2010 Tied for Warmest Year on Record (2010) that 2009 tied with a cluster of years 1998, 2002, 2003, 2006 and 2007 for the second warmest year behind record holding 2005 since 1880 and 2010 tied for the warmest in recorded history with 2005. They add (GISS Surface Temperature Analysis: 2008 Was Earth's Coolest Year Since 2000, 2008) that the unusual warmth in 2007 was especially important because it occurred at a time when solar irradiance was at a minimum and the equatorial Pacific Ocean was in the cool phase of its natural El Niño-La Niña cycle. Grimaud and Tournemaine (2007) reported that linear warming trend over the 50 years from 1956 to $2005\left(0.13^{\circ} \mathrm{C}\right.$ per decade) was nearly double from 1906 to 2005. Authors also reported that the global average sea level rose at an average rate of 1.8 mm per year over 1961 to 2003 and at an average rate of about $3.1 \mathrm{~mm}$ per year from 1993 to 2003.

Global warming can have numerous consequences, some more, some less problematic, and even positive, for some areas. Watkiss et al. (2004 and 2005), for example, claimed that the major consequences on European and global level were : (1) changes in natural environment (impacts of sea rise, erosion, loss of coastal land, impacts on water resources (supply and quality), impacts on ecosystems and the loss of biodiversity, potential droughts and flooding, extreme weather conditions, and other, (2) changes in human health (impact on human health from changes in cold related and heat related effects and impacts on human health from the disease burden (and other secondary effects); (3) impacts on economic elements (agriculture, energy use, water resources, supply and quality, changes to tourism potential and impact on destinations, damages from extreme weather and other). Of course, all climate change impacts could mirror themselves in damages to economic system and growth, some directly, other indirectly, some soon, other in the longer run.

Estimates of economic impacts of 'inaction' differ, but nonetheless they are significant. The Stern review (2006, pp. 143-158) reports that the cost heavily depends on the actual progress of warming, which is associated with a lot of uncertainty, especially if projecting the changes for the next century or more. The Review reports that most studies so far have used an assumption of $2-3{ }^{\circ} \mathrm{C}$ additional warming, which is calculated to lead to a $0-3 \%$ loss of global gross domestic product (GDP) on average, with poor countries suffering higher cost. But, as Stern review stresses 'business as usual' could lead to higher increases in global temperature, which would increase the scope of negative impacts, leading to GDP losses of $5-10 \%$ globally, with poor countries suffering most².

The concern about the environmental change is not as new as it seems; it dates roughly three decades into the past. Although the concept of sustainable development has its formal source in the World Conservation Strategy form 1980, its popularization is connected with Brundtland report (1987) and the establishment of World Commission on Environment and Development. The breaking point for the global acceptance of the concept of sustainable development was the UN Conference on Environment and Sustainable Development held in Rio de Janeiro in 1992, known as the "Earth Summit" that defined the meaning of the phrase "sustainable development" as the alignment of economic growth, on the one hand, and rational use of natural resources, on the other side. The Earth Summit was followed by numerous

\footnotetext{
1 The empirical research greatly benefited also from the comments, suggestions and ideas obtained from M. Jana Prešern (Aragon agency) and Irena Ograjenšek (Faculty of Economics, University of Ljubljana). The empirical analysis is a part of a broader research on happiness factors in Slovenia. The preliminary results were presented at the 2012 Odyssey conference in Sibenik, Croatia.

${ }^{2}$ Although, due to uncertainty the actual losses could be much higher. Also, the Review stresses that if the models took account of three additional factors (on the environment and human health, the higher responsiveness of climate to GHG emissions and the disproportionate impact on poorer economies), the cost would even increase, leading to lower per capita consumption by approximately $20 \%$ now and forever (5-11\% for environment impact and human health, 5-14\% for the costs related to higher elasticity of climate change to GHG emissions). In 2005 alone, global economic losses from natural disasters exceeded \$ 200 billion (Esty and Winston, 2006).
} 
documents on sustainable development (e.g. the Kyoto Protocol in 1997, Millennium Declaration in 2000, The Stockholm Convention in 2001 and others) and it became an integral part of all strategic and other development documents.

Sustainable development, with the aim of meeting the needs of present generations without compromising the needs of future generations, is based on three main aspects: the balanced economic growth (economic aspect), respecting and promoting social and human rights (social aspect) and the protection and preservation of the environment (environmental aspect). That way sustainable development achieves a balance between the demands for improving quality of life, the realization of social welfare and peace for all and the requirements for preserving elements of the environment as a natural resource. The environmental aspect of sustainable development needs to have special attention due to the warning data on the ubiquitous destruction of environment, eco system, water resources and others.

But how sustainable is our development? In recent years, we can notice the great improvements considering the information access and research related to sustainable development measurement at the international level, granting also access to internationally comparable data.

To illustrate the attitudes and development in the field of environmental protection, we use the Environmental Sustainability Index (ESI). The ESI ${ }^{3}$ measures and compares the country's ability to protect the environment over the next few decades. EPI aims to measure a country's overall contribution to environmental conservation, taking into account the main global environmental problems and the ways in which a specific country faces them. It does so by integrating 76 data sets into 21 indicators of environmental sustainability, including natural resources, past and present pollution levels, environmental management efforts and the ability of companies to improve their environmental performance. In other words, the objective of the index is to evaluate the environmental sustainability of the country in comparison with other countries (Environmental Sustainability Index: About ESI, 2013). EPI is an instrument that gives a result in terms of indices ranging from 0 to 100 and includes available data from 25 different critical categories (like fishing, carbon emissions, preservation of forests and water, etc.).

Figure 1: The first 28 countries by EPI index in 2012*

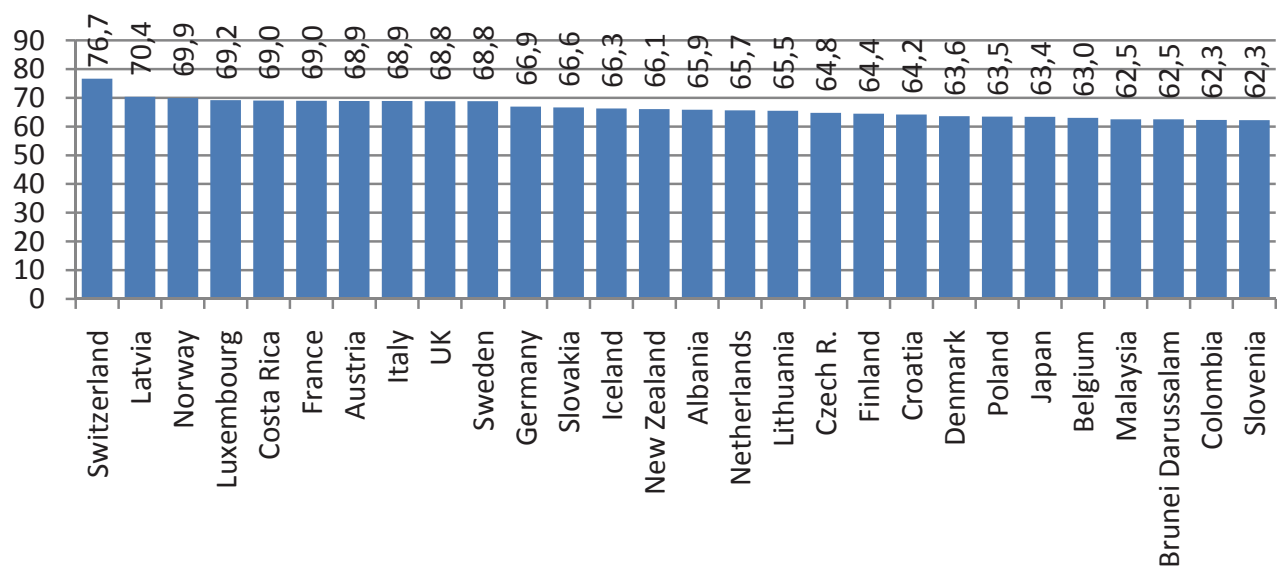

*132 countries were examined in total.

Source: Yale Center for Environmental Law and Policy, p. 4.

ESI country rankings from 2012 report are shown in the Figure 1. Switzerland achieved the best results and its superior performance stems largely from the high results achieved in the field of health eco - system, primarily quality of air and water. Switzerland was followed by Latvia, Norway and Luxemburg, while Slovenia was ranked $28^{\text {th }}$. The country performed well primarily in the field of forest and water resources (ESI, 2012).

${ }^{3}$ ESI was jointly developed by Yale's Center for Law \& Environmental Policy and Columbia's Center for International Earth Science Information Network in collaboration with the World Economic Forum and the Joint Research Centre of the European Commission. ESI was published 4 times: in 2000, 2001, 2003 and last time in 2005 when EPI (Environmental Performance Index) was developed and consequently firstly published in 2006 as a pilot study (then in 20082010 and 2012). 
The question is why some societies perform better in terms of sustainable development and why some perform worse. If we limit the discussion only to the ecological part of sustainable development, at least three points can be made: natural conditions, economic development and the attitudes of the society towards sustainable development. Our discussion will in continuing be limited to the last.

\section{The role of consumption in building a sustainable society}

'The cornucopia of consumption goods continually produced by the industrial system and lavishly displayed in stores and supermarkets of industrial countries has often been considered as the symbol of successful economic performance of modern capitalist economies' (Cogoy, 1999, p. 385). The performance of the economy is and was measured in GDP, which represents the monetary value of all goods and services produced in an economy (see System of national accounts, 2008). In line with the consumerism goal of a capitalist society, GDP generally neglects 'bads' produced in a society, from environmental damage to social problems like crime, which it also admits (System of National Accounts, 1993). Such orientation, of course, is not supportive to developing a sustainable economy.

\subsection{Consumption and sustainability}

The religion of consumerism is the essential problem of building a sustainable society, if the mantra of 'I want to consume more' does not change. Such an approach has also been the essential premise in economic theory. Consumer behaviour in economics is often modelled as rational, utility maximizing behaviour (e.g. Barro and Sala-i-Martin, 1999).

For the purposes of building a sustainable society, a consumption maximizing agent with a standard preference set is unsuitable. But the reality is that most often consumers, economic agents, do not solely maximize their selfish consumption, but also receive benefit or utility from consuming less, differently or from 'consuming' the fact of their charitable behaviour. Wagner (2006) speaks about an American artist Georgia O'Keefe who lived her frugal life in 1940s in New Mexico, enjoying her minimalist consumption there and spending less and less time in affluent New York City. Wagner $(2006$, p. 659) speaks about this example as a challenge to the 'more is better' axiom of the neoclassical consumer theory. Cogoy (1999) stresses that the consumers have a long list of alternative possibilities when deciding about that consumption and both the list and the choices are co-determined by the society one lives in and its cultural norms. Therefore, we can say that they are at least partially learned and imposed on us. Ulhoi et al. (1996) mention that the public concern over environmental problems has been rising. Such concerns can change the process of choice and list creation. The problem of maximization must therefore be first carefully reshaped into the problem of preference formation and only then the impact of the consumer can be examined in a growth framework. As Hart (2002) proposes, the relationship between culture and growth must be examined.

Therefore, we follow a more general approach to maximizing consumption, which was introduced already in 1970s (a noted article by Georgescu-Rogen ${ }^{4}, 1971$ ). Consumption can alternatively be viewed also as all kinds of activities that an individual pursues in order to obtain life-enjoyment. Consequently, consumption can be viewed in much broader sense; it can refer to goods, services, skills, environmental goods and values, social relationships, culture, information and so on. Therefore, consumers select from a much broader array than solely 'goods' and some of these choices actually can mean consuming less or consuming differently. Such an approach can support the development of a sustainable society trough environmental aspect.

As shown with the data above and as Cogoy (1999) claims - the consumer is a social and environmental actor. Why? Looking from the perspective of long term development patterns, the consumer has a huge impact on the structure and nature of production via his consumption decisions. The companies are motivated to redirect their efforts to produce goods that are sought for and use the technology that is acceptable. During the past, there was a lot of negative publicity over child labour, a lot of positive publicity for green production, corporate social responsibility demonstrated in charitable activities and so on. Given that, publicity is very important part of corporate image and therefore impacts market shares of companies, companies will place a lot of emphasis on indulging the consumer. Of course, one must not overlook the power of value creation, which is a process impacted by consumers, firms and governments. Consumerism was also learned, it developed gradually, first in the US, then Europe and now it is becoming a major source of growth also in

\footnotetext{
${ }^{4}$ Nicholas Georgescu-Roegen (1906-1994) was an American (Romanian born) economist who dealt with the problem of capitalism and published an article 'Mathematical Proofs of the Breakdown of Capitalism' in Econometrica in 1960. Otherwise, the author is most known for the concept of de-growth which means that economic growth can not continue forever. The model is presented in his 1971 book The Entropy Law and the Economic Process.
} 
emerging markets (e.g. China) (more on this topics see Sanne, 2002, Jackson and Papathanasopoulou, 2008). Within the context of a sustainable society, the consumer must be viewed as a key element of successful transition from a traditional to sustainable society.

\subsection{Modelling growth, environmentally friendly consumer and the sustainability issue}

A sustainable economy model requires a changed pattern of consumption. We shall assume that such learning and transition from the standard capitalist consumerism is possible due to both many practical examples and academic research (see Lintott, 1998, Jackson and Marks, 1999, Jackson, 2002, Buenstorf and Cordes, 2008, Jackson and Papathanasopoulou, 2008). Nonetheless we are aware of potential problems (e.g. Hart, 2002, Jackson, 2002, Buenstorf and Cordes, 2008), which will be dealt with later on.

We have developed a simple dynamic growth model that deals with the impact of utility or preference formation on economic growth. The utility in the model depends on the quality of natural environment. The model is for clarity kept simple, yet it does not necessarily lose much in terms of content.

The model is inspired by a model prepared in 2002 by Sinclar-Desgagne, which examines the importance of aspirations for growth. People in his society can either have low aspirations (culture or poverty) or high aspirations when striving for wealth and power. We have redesigned the model to fit our needs ${ }^{5}$. First of all, we have adapted the concept of aspirations. The aspirations will be interpreted into this model as a desire for high quality natural environment (high aspirations) or a lack of it (low aspirations). Similarly to the logic in the Sinclar-Desgange (2002) high desire for good quality environment (in the original article high aspirations for wealth, power) leads to high marginal utility of good quality environment for the consumer and low desire to low. Of course, if a consumer has a strong desire for good quality environment, low levels or amount of high quality environment leads to overall low utility and vice-versa. Additionally, we have assumed the presence of the 'learning effect' - if in a specific economy the amount of natural capital, (which will be used as a synonym for increased capital (growth opportunities) in a green setting, so a type of development model that is sustainable, ensuring growth but at the same time preserving the environment) - increases, more and more individuals will be learning by doing and through experience that nature is a quality that changes their lives and impacts their utility.

The representative agent's utility function is inspired by the Sinclar-Desgange $(2002)^{6}$, although significantly changed in specification and logic. The function is shortened and instead of seeking aspiration from wealth, people seek aspiration from environmental quality or nature $(\mathrm{N})$. The rest of the notation in the model is standard: $k$ is physical capital, $\mathrm{C}$ is consumption, $\mathrm{V}$ is value function. The utility of the agent at a consumption level $\mathrm{c}$ is adjusted from the standard growth setting.

$$
U=a(N) V(c)
$$

The $V(c)=\frac{c^{1-\sigma}}{1-\sigma}$ is the standard function of utility used in growth models (see Barro and Sala-i-Martin, 2005) and it is the constant intertemporal elasticity of substitution (CES) utility function. $a($. ) is used also in the Sinclar-Desgange $(2002)^{7}$ model and explains how overall utility depends, not just solely on material (standard neoclassical) consumption, but also on the natural quality in our case, $N$. We substitute capital $(k)$ with the variable $N$, which will describe the quality of nature. It is interpreted as a coefficient. If $N$ drops below 1 , that means that the quality of the environment has deteriorated and that therefore, with stable physical capital, overall natural capital is lower and this will have a negative impact on overall utility, because of the contribution through a, which impacts the marginal utility of material consumption and is non-negative in first derivative, but negative in the second, therefore concave.

So far, past experience speaks in favor of the relationship presented in Figure 2. Anthropogenic GHG emissions have increased significantly since the beginning of the industrial revolution (Sterman and Sweeney, 2002). Therefore, increased material wealth leads to lower environmental quality. For educated consumer, striving for not solely maximizing consumption, but also his well-being, the quality of the environment would reduce his overall utility.

\footnotetext{
${ }^{5}$ The notation in the Sinclar-Desgagne (2002) model is standard growth notation, such as $c$ for consumption, $k$ for capital, $V$ for value function, therefore, for the purpose of clarity we stick with the standard growth notation.

6 The original article uses the following specification: $U=a(k) V(c)$

7 In the cited article, the focus is on high and low aspirations society, one that strives for wealth and power and one that does not. Therefore, the focus is only on physical capital. Also, as noted in footnote 3, the function is extended by also b(.) with a similar logic as a(.).
} 
As we shall see, the discussion will be based primarily around function a(.), which determines the utility formation of the individual based on the quality of the environment. High or low desire for high quality environment impacts the utility formation and therefore the balanced growth path in this simple dynamic economy.

Figure 2: Possible link between quality of the environment and capital and output

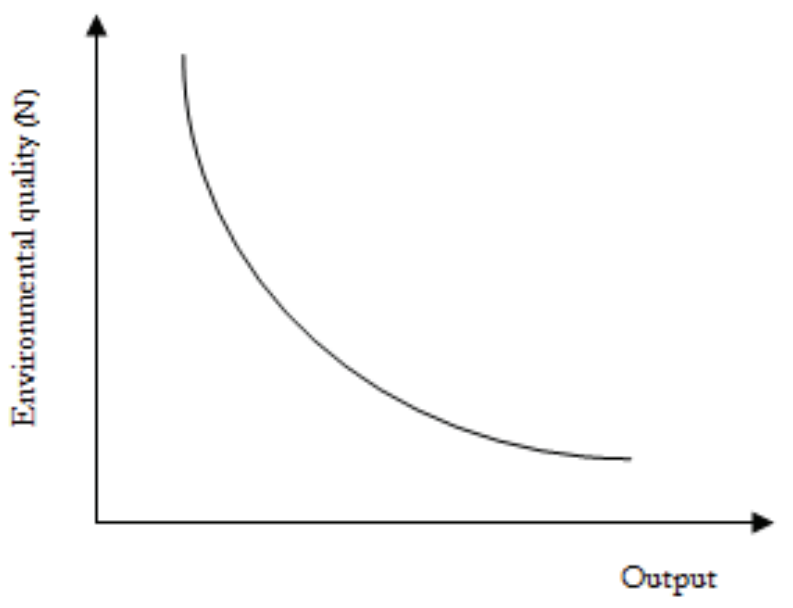

The other side of the model, the physical capital accumulation process, is standard. We have use the AK model, also used in the Sinclar-Desgange (2002) article, but we have extended it to add depreciation ( $\delta$ ) as is usually done in growth models. The change in the physical capital depends on the total output in the economy, which depends on technology $(A)$ and capital $(k)$, and consumed part $(c)$. Increase in capital $(k)$ induces an increase in production.

$$
\dot{k}=A k(t)-c(t)-\delta
$$

Natural capital, $N$, will not enter the capital formation equation. Natural capital is a variable that does not impact physical capital formation, but can depend on it, as environmental research shows, primarily in a negative manner (e.g. the already mentioned Sterman and Sweeney, 2002). For now, we have assumed it can change exogenously, for the purposes of simplicity and clarity of this model. Alternatively, the quality of the environment could be endogenously determined by the rate of change in physical capital and/or preference formation ${ }^{8}$.

The model is relatively simply solved in a dynamic growth context. In the indefinitely lived society, the representative agent's problem can be represented by system of equations, solution which gives the answers to the question on the impact of desires (impact of $a$ and $b$ ) for high quality environment on growth. The maximizing problem can be set as follows:

Such that:

$$
\max _{c(t)} \int_{0}^{\infty} e^{-\rho t} U(t) d t=\max _{c(t)} \int_{0}^{\infty} e^{-\rho t}[a(N(t)) V(c(t))] d t
$$

$$
\begin{gathered}
\dot{k}=A k(t)-c(t)-\delta k \\
k(0)=k_{0} \\
c(t), k(t) \geq 0
\end{gathered}
$$

8 It can be assumed that consumer preferences for clean environment will stimulate the companies to produce in a more environmentally friendly manner. Therefore, increased desire (preference formation) can impact the natural capital. At the same time also production increase is not necessarily linked solely to lower $N$, but technology change can induce a different process that at the same time allows larger production. 
Also, remember that $V(c)=\frac{c^{1-\sigma}}{1-\sigma}$, which we enter into the FOCs to simplify the final solution and obtain the balanced growth path. We assume that $\mathrm{N}$ does change in time (we discuss this option in discussion), but in terms of the model we assume it can change only exogenously. This simplification is another possibility for future extension of the model.

The dynamic optimization Hamiltonian equation must be prepared in order to solve this problem, $\mathrm{t}$ is dropped in the equation in the arguments of $k(t)$ and $c(t)$ :

$$
H(k, c, \mu, t)=e^{-\rho t}[a(N) V(c)]+\mu(A k-c-\delta k)
$$

Taking the derivatives provides a set of first-order conditions (transversality condition also holds) that help us find the solution to the model:

$$
\begin{gathered}
H_{c}^{\prime}=e^{-\rho t}\left[a(N) V_{c}^{\prime}\right]+\mu=0 \\
H_{k}^{\prime}=\mu(A-\delta)=-\dot{\mu}
\end{gathered}
$$

Logarithms and time derivates lead to the solution. The optimal growth path in this economy is given by:

$$
\frac{\dot{k}}{k}=\frac{\dot{c}}{c}=\frac{1}{a(N)}(A-\delta-\rho)
$$

Optimal growth path in the economy is characterized by the equality of capital and consumption growth. Without the inclusion of the preference formation factor a(.), this would result in a standard AK model solution. But since the model has been extended for the possibility that aspirations or desires about the quality of natural environment can actually impact the total utility of material consumption by lowering it if natural quality is poor or increasing it if natural quality is high, the impact of preferences about the nature on growth of consumption and consequently on growth in the economy can be observed.

The main interest of the model lies in the interpretation of the function $a(N)$, which determines the impact of the quality of the environment on the individual utility formation, which depends on two aspects: (1) impact of the environmental quality $a(N)$ and (2) direct utility of material consumption $V(c)$.Together, both determine the individual's utility from consumption $U=a(N) V(c)$. Remember, that $a(N)$ represents the aspirations or desire for either higher or lower quality environment. If the aspirations for higher quality environment increase, the desire for less pollution increases, this will lead to an increase in a(.) and consequently will lower growth of consumption $\frac{\dot{c}}{c}$ and consequently also economic growth. The intuitive link can be identified through the anecdotal evidence mentioned earlier. The desire for higher quality environment will lead in time to lower consumption (or consumption growth) and because of the link between production and GHG emissions also in time to better environmental quality. Low aspirations or desire for clean environment allow fast growth rates of consumption and thus growth.

The point of this simple exercise is to show that utility formation can in fact have an impact on economic growth. And it is the preferences of the consumers that determine, whether sustainability is a real option for an economy. In this simple model, the result of the model is that higher aspirations for the environment actually depress growth. But the model could be extended in several ways to account for potential shortcomings.

First, if a multi-sector model were used as a foundation of this exercise, it would be possible to model how increased importance of the environment for the people can actually cause sectoral shifts in the economy. One sector (polluters, for example) would be hurt, but overall economic growth in the economy could actually increase due to the positive impact on other sectors (for example, green consumer products).

Also, aspirations can impact technological development. Given that technological development is expensive and risky in terms of product and processes placement in the market, green aspirations with the consumers would actually cause more innovation in eco-production and consequently increase productivity and choice in the sector. In turn, this would also allow a decrease in prices of such technology and higher demand. Again, there is a positive loop.

Third, it would be possible to include the environmental quality directly in the production function and thereby endogenize the change in environmental quality. Similarly, also preference formation could be specified in an endogenous manner.

But so far, the model has indicated that consumers matter for economic growth and sustainability, which was the primary goal. Now the question is: how ready are they? 


\section{Are consumers ready to become 'green'? The case of Slovenia}

\subsection{Methodology}

In continuing we provide an illustration of the general attitudes of Slovenian population and consequently examine the readiness of Slovenia to become more sustainable. The empirical analysis is based on survey results, conducted in May 2011 with the assistance of an agency specialized in the research of public opinion. Stratified sampling was used in order to capture the characteristics of the population.

The questionnaire consisted of 8 structured questions. The research focused on two elements: examining the determinants of happiness among Slovenian population and the importance of sustainable development components to them.

The sample consisted of 800 individuals, $51.9 \%$ men and $48.1 \%$ women. The age of the respondents was between 15 and 65 years, each 5-year age group represented approximately 10 percent of the sample. The majority of respondents finished secondary education (4 or 5 year programmes, $44.5 \%$ ) or had a university degree. The share of those with no degree was $5 \%$ and the share of those with MSc and PhD combined was $4.1 \%$. The majority of respondents (43.8\%) were working, $18 \%$ were still in the process of education, while $14.4 \%$ were retired.

\subsection{Results}

Unfortunately, the results show that the people in Slovenia are in general not well acquainted with the concept of sustainable development. About half of people believe to be familiar with the concept. Interestingly, men are on average more familiar with it, they prevail among those that are familiar with the concept with $54.5 \%$ over women $(45.5 \%)$. Also, among all men $31.8 \%$ are familiar with the concept, while less than $30 \%$ of women are.

The differences among age groups in their familiarity with the concept exist, but are not dramatic. 26 to 30-year olds are most acquainted with the concept: $37.9 \%$ know the concept of sustainable development, followed by $31-35$ year olds $(36.4 \%)$ and $36-40$ year olds (32.9\%). The young have significantly smaller knowledge of the concept (only $13 \%$ of those aged 15 to 20 ). But $25.9 \%$ of oldest (61-65 years) are familiar with it, which is surprising, given that the younger population would be expected to know the concept from school 9 .

Education is also a factor of knowledge about sustainable development. Even $54.5 \%$ of those with MSc. or higher education know the concept, followed by $41.1 \%$ of those with university degree and $25.8 \%$ of those with secondary school degree, while only $2.5 \%$ of those with unfinished primary school an $17.9 \%$ of those with vocational training (2-3 year programmes) are familiar with the concept of sustainable development.

Those that claimed to know the concept of sustainable development were also asked to briefly summarize its main characteristics, given that people often overrate their knowledge (Table 1). We were surprised to see that despite the fact that many people relate the concept of sustainable development to environmental issues, many were aware of the triple notion of the concept.

Table 1: Selected definitions of sustainable development (242 answers were received in total)

\section{Please, briefly describe the concept of sustainable development.}

Economic development, environmental protection and the development of the society in a positive direction.

Sustainable development is a vision of progress that encompasses economic development, social protection, social justice, and the values of sustainability are recognized by global leaders.

A rational behaviour of people so that they do not deplete natural resources.

It is a coexistence of social, economic and environmental development and the intent that this cohesion leads to a higher quality of life for all people who can grow also personally by behaving so.

Not to destroy our nature so that our children and grandchildren also have them at their disposal.

Human behaviour that does not depend on only profit maximization, but also takes into account the local and general natural environment.

\footnotetext{
${ }^{9}$ Already some kindergardens have implemented recycling and serve integrated farming produce in their meals.
} 


\begin{tabular}{|l||}
\hline Co-existence with the basic natural laws. \\
\hline A development based on the idea of 'giving back to nature'. \\
\hline The society must plan for the future, including the size of population. \\
\hline $\begin{array}{l}\text { It is the type of development that allows the development of everybody throughout their lives, but does not limit } \\
\text { others in doing the same. }\end{array}$ \\
\hline Use of renewable sources. \\
\hline Continuity of social, environmental and economic development. \\
\hline
\end{tabular}

Data: Survey, 2011.

We further investigated the knowledge of sustainable development by asking about the components. On average (part 'All' in Table 2), people are most familiar with the environmental component of sustainable development, and least with economic (Table 2).

Table 2: Statements on sustainable development*: Do you agree with the following statements?

\begin{tabular}{|c|c|c|c|c|}
\hline 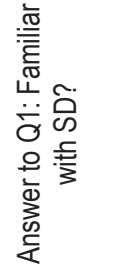 & & $\begin{array}{l}\text { Sustainable development } \\
\text { deals with the problem of } \\
\text { environmental protection, } \\
\text { use of natural resources } \\
\text { and the ability to grow and } \\
\text { develop with the nature. }\end{array}$ & $\begin{array}{l}\text { Sustainable development } \\
\text { deals with the development of } \\
\text { the society, social protection } \\
\text { and security, equality, peace, } \\
\text { etc. }\end{array}$ & $\begin{array}{l}\text { Sustainable development } \\
\text { refers also to economic } \\
\text { progress, economic } \\
\text { development, growth. }\end{array}$ \\
\hline \multirow[t]{3}{*}{ All } & $Y$ & 80,5 & 79,0 & 71,1 \\
\hline & $\mathrm{N}$ & 2,8 & 3,9 & 7,8 \\
\hline & NK & 16,8 & 17,1 & 21,1 \\
\hline \multirow{3}{*}{$\begin{array}{l}\text { Yes, I } \\
\text { am } \\
\text { familiar } \\
\text { with SD. }\end{array}$} & $Y$ & 967 & 926 & 802 \\
\hline & $\mathrm{N}$ & 2,1 & 3,3 & 9,9 \\
\hline & NK & 1,2 & 4,1 & 9,9 \\
\hline \multirow{3}{*}{$\begin{array}{l}\text { No, not } \\
\text { familiar } \\
\text { with SD. }\end{array}$} & $Y$ & 73,5 & 73,1 & 67,2 \\
\hline & $\mathrm{N}$ & 3,0 & 4,1 & 6,8 \\
\hline & NK & 23,5 & 22,8 & 26,0 \\
\hline
\end{tabular}

${ }^{*} Y$ - yes, N-no, NK-do not know

Data: Survey, 2011.

The difference between the knowledge of these dimensions is especially pronounced among those that claim to actually know the concept (part 2 of table: Yes, I am familiar...'). While over $96 \%$ agree that sustainable development deals with environmental protection, only $80 \%$ agree that the concept also has economic growth ambitions. This leads us to believing that in general, sustainability is nonetheless most strongly related to environmental protection and less to the social and economic dimension. 
Table 3: Attitudes towards selected elements of sustainable development (agreement on a scale 1-5)

\begin{tabular}{|l|c|c|c||}
\hline \hline Item & Mean & Mode & \% with modal answer \\
\hline Global warming cannot be stopped. & 3,11 & 3 & 27,1 \\
\hline $\begin{array}{l}\text { Corporate responsibility is very important for successful implementation of } \\
\text { sustainable development }\end{array}$ & 4,56 & 5 & 63,5 \\
\hline $\begin{array}{l}\text { In order to keep the eco-systems working efficiently, their balance must be } \\
\text { preserved. }\end{array}$ & 4,60 & 5 & 66,8 \\
\hline $\begin{array}{l}\text { Individuals should be educated about the importance of sustainable development. } \\
\text { It is important to preserve nature and natural resources so that our children can } \\
\text { also benefit from them. }\end{array}$ & 4,68 & 5 & 56,6 \\
\hline \begin{tabular}{l} 
The state should tax the production that is harmful to the environment. \\
\hline $\begin{array}{l}\text { The state should stimulate by lower taxation and subsidies the use of } \\
\text { environmentally friendly technologies (green cars, green farming, eco food, etc.) }\end{array}$
\end{tabular} & $4,4,67$ & 5 & 75 \\
\hline Sustainable development is not discussed enough in public. & 4,45 & 5 & 59,1 \\
\hline $\begin{array}{l}\text { The consumers can significantly influence the companies and their environmental } \\
\text { behaviour with the choice of products that we buy. }\end{array}$ & 4,22 & 5 & 73,6 \\
\hline
\end{tabular}

Data: Survey, 2011.

We also investigated individuals' attitudes towards general aspects or policy approaches that would help sustainable development (Table 3). In order to obtain their view on what they feel is the appropriate social orientation, what the society and the state should do, we asked the respondents to rate very general statements on a scale 1 to 5 (1completely disagree, 5 - completely agree). The results show that the individuals highly agree with the importance of sustainable development and on a generalized level also support changes.

The results show that the Slovenian population is very knowledgeable about sustainable development and also very supportive to it. But the statements in the first part were very general and were not addressing the individual and his/her actions much. Since it is much easier to agree with general statements than actually changing own attitudes or behaviour we examined also the importance of sustainable development for the individuals, their own actions and attitudes using the concept of happiness. Our belief is, that if something impacts the happiness of an individual, for example in a positive manner, he/she will be more motivated to behave so as to improve the situation and thereby positively influence his/her happiness. For example, if one values leisure and leisure increases his happiness, he will be prone to devoting more time to it than someone who does not value leisure as much. The same logic applies to the components of sustainable development. If an individual values clean environment, he will be more likely to accept the need for recycling, accept and buy (more expensive) ecologically produced food etc. Therefore an understanding of happiness determinants provides information about the support to sustainable development.

We investigated closely a series of potential happiness determinants. Results (Figure 2) indicate that sustainable development is not high on the priority list of individuals. Slovene population is quite traditional, health, personal freedom, trust, love, family and happiness of loved ones are most important. Factors like clean environment and clean air are important, but social cohesion, equality, green food and other elements that are related to sustainable development much less. 
Figure 2: Determinants of happiness: Does the factor contribute to your happiness (\% of people that chose a specific factor as important)

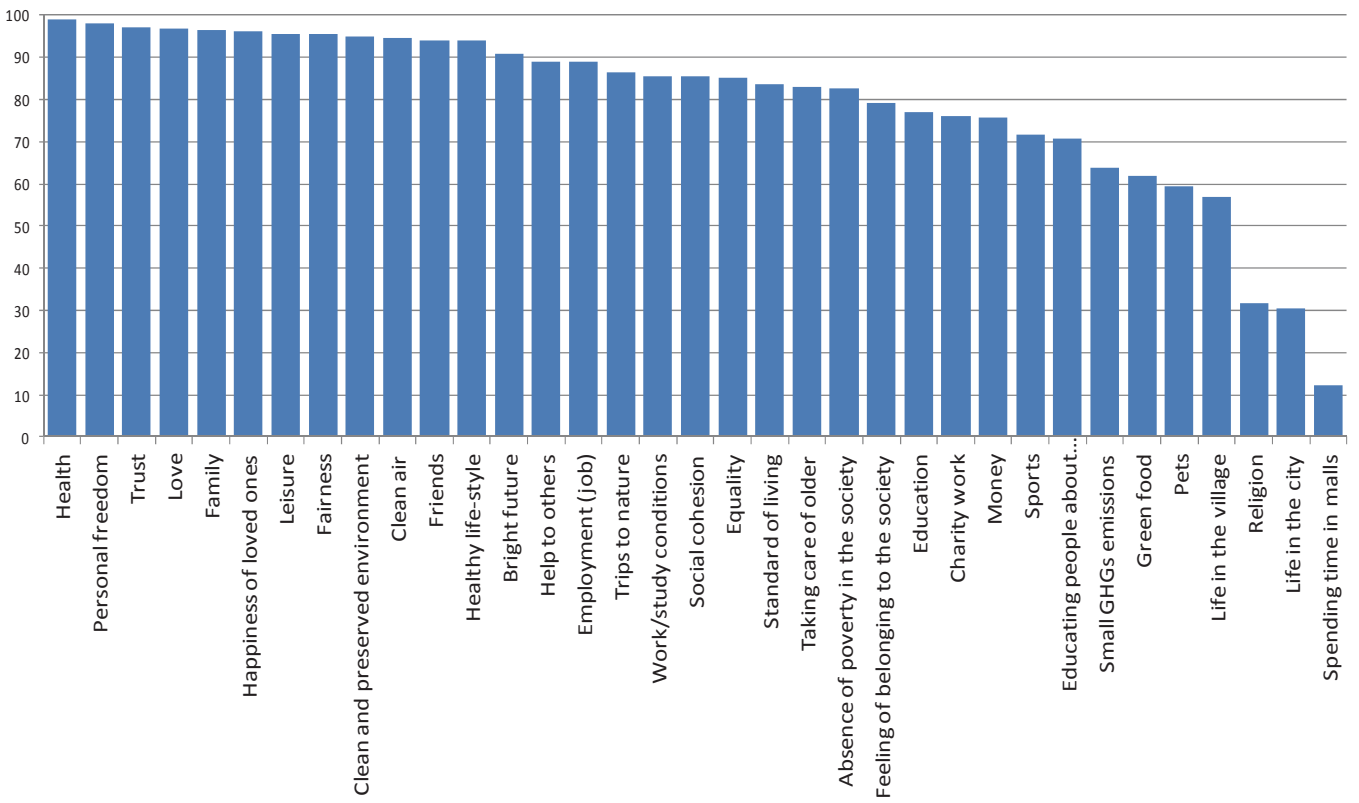

* Respondents could choose as many factors as they wanted. For each factor they stated, if it does (Yes) or does not (No) contribute to their happiness.

Data: Survey, 2011.

It was interesting to see whether individuals actually contribute to increasing their happiness factors by being actively involved in activities related to them. Figure 3 summarizes the results. Individuals invest most in their loved ones and friends. This answer is also expected, given that both elements are high on the happiness factors ladder. Surprisingly, also elements of sustainable development are very highly ranked. The highest ranking has the 'compact light bulb use'. But given that this is cost efficient and that it has been for a while to buy the standard-sized energy inefficient bulbs, the high ranking is not completely exogenous. It is however encouraging to see other factors of sustainable development ranked high (recycling, behaving eco-consciously, helping neighbours and elderly and other). These are also the elements that are linked to higher costs or time consumption and are not demanded by the state. Therefore, people are being active in the field of sustainability. Interestingly, religion ranked last.

The results of the study show that Slovenians are quite traditional, health, personal freedom, trust, love, family and happiness of loved ones are the elements that were most often chosen as those that are important for individual's happiness. What about sustainable development elements? Elements like clean environment and clean air are important, but social cohesion, equality, green food and some other elements that are related to sustainable development much less. In terms of what the results imply for the potential of sustainable development in Slovenia, we see that the environmental component is strongest, although, unfortunately none of the elements of sustainability rank very high on the 'happiness scale'. Therefore, it is very important that the state invests in educating its 'consumers' so that they become more environmentally oriented. 
Figure 3: How do you try to increase your happiness? Average answer*

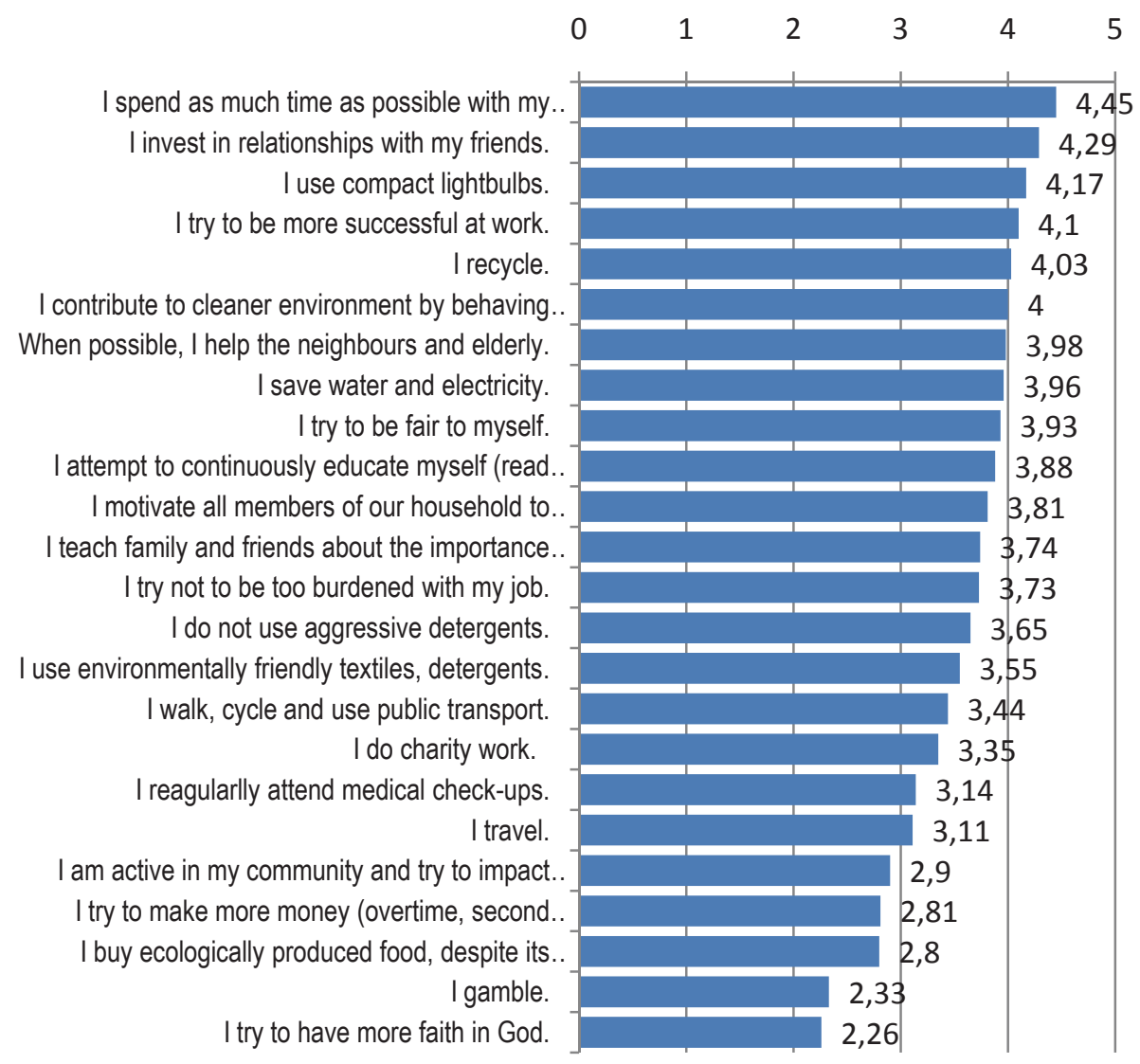

*Answers on a scale 1-5 (1- never, 5-always).

Data: Survey, 2011.

\section{Conclusion}

Sustainable development, defined as environmentally friendly and more socially acceptable economic growth and development, has three major components: environmental, economic and social. The research examines the possibility of implementation of sustainable development in a theoretical and empirical context.

The purpose of the article was to examine the role of consumption and the formation of consumer preferences for economic growth and the implementation of sustainable development. Sustainable development depends on the existence of a specific (not standard, consumption maximizing) consumer. We have developed a model of a new, environmentally oriented consumer, which has environmental aspirations as a constituent part of his values. Consumers are social agents that are capable of changing their utility (well-being) maximization patterns and their attitude towards relative importance of different factors. Thereby, consumers impact their consumption habits, but also give an important signal to the market and producers. Consequently, the consumer is the key in the process of transition to a sustainable growth model.

To empirically illustrate the model, we used the survey data from the 'Happiness factors research for Slovenia'. The data show that Slovenians are generally very traditional, with family, friends, health, love, personal freedom being most important for their happiness. Nonetheless, the environmental elements of sustainable development do carry some 
weight. Primarily, it is also important to note that the younger generations are better familiar with the concept, implying that in the future the direction of Slovenian consumers is actually going towards being more green.

\section{References}

Barro, R. K. \& Sala-i-Martin, X. (1999). Economic growth. Cambridge, Mass.: MIT Press.

Brundtland Report: Our Common Future, Report of the World Commission on Environment and Development, World Commission on Environment and Development. (1987). Published as Annex to General Assembly document A/42/427, Development and International Co-operation: Environment August 2, 1987. Retrieved, February 10th 2012, from: http://www.un-documents.net/wced-ocf.htm.

Buenstorf, G. \& Cordes, C. (2008). Can sustainable consumption be learned? A model of cultural evolution. Ecological Economics, 67(4), 646-657.

Cogoy, M. (1999). The consumer as a social and environmental actor. Ecological Economics, 28(3), 385-398.

Environmental Sustainability Index: About ESI. (2013). Retrieved, January 24th 2013,http://sedac.ciesin.columbia.edu les/esi/ESI2005_policysummary.pdf.

Esty, D. C. \& Winston, A. S. (2006). Green to gold: How smart companies use environmental strategy to inovate, create value, and build competitive advantage. New Haven and London: Yale University Press.

GISS Surface Temperature Analysis. (2008). Was Earth's Coolest Year Since 2000. NASA, Goddard Institute for space studies. Retrieved, February 10th 2012,http://www.giss.nasa.gov/research/news/20090223/.

GISS Surface Temperature Analysis: Global Temperature Trends: 2007 Summation. (2007). NASA, Goddard Institute for space studies. Retrieved, February 8th 2012,http://data.giss.nasa.gov/gistemp/2007/.

GISS Surface Temperature Analysis. (2010). NASA Research Finds 2010 Tied for Warmest Year on Record. NASA, oddard Institute for space studies. Retrieved, February 10th 2012, from: http://www.giss.nasa.gov/research/news/20110112/.

Global Footprint Network. (2012). Retrieved, February 10th 2012, from: http://www.footprintnetwork.org /en/index.php/GFN/page/world_footprint/.

Grimaud, A. \& Tournemaine, F. (2007). Why can an environmental policy tax promote growth through the channel of education? Ecological Economics, 62(1), 27-36.

Hart, R. (2002). Growth, environment, and culture--encompassing competing ideologies in one 'new growth' model. Ecological Economics, 40(2), 253-267.

Jackson, T. \& Marks, N. (1999). Consumption, sustainable welfare and human needs--with reference to UK expenditure patterns between 1954 and 1994. Ecological Economics, 28(3): 421-441.

Jackson, T. (2002). Evolutionary psychology in ecological economics: consilience, consumption and contentment. Ecological Economics, 41(2), 289-303.

Jackson, T. \& Papathanasopoulou, E. (2008). Luxury or [']lock-in'? An exploration of unsustainable consumption in the UK: 1968 to 2000. Ecological Economics 68(1-2), 80-95.

Lintott, J. (1998). Beyond the economics of more: the place of consumption in ecological economics. Ecological Economics, 25(3), 239-248.

Sanne, C. (2002). Willing consumers--or locked-in? Policies for a sustainable consumption. Ecological Economics, 42(1-2), 273287.

Sinclar-Desgagne, B. (2002). Endogeneous aspirations and economic growth. Retrieved, March 15th 2012, from:neumann.hec.ca/chaireing/art/aspirations.pdf.

Sterman, J. D. \& Sweeney L. B. (2002). Cloudy Skies: Assessing Public Understanding of Global Warming. System Dynamics Review, 18(2), 36-49.

Stern, N., (2006), Stern Review: The economics of climate change «. Her Majesty's Treasury. [Online] Available: http://www.hmtreasury.gov.uk/independent_reviews/stern_review_economics_climate_change/stern_review_report.cfm (July 24, 2012)

System of National Accounts. (2012). United Nations Statistical Division. [Online] Available: http://unstats.un.org/unsd/sna1993/toctop.asp (April 30, 2012)

The Earth Summit. United Nations Conference on Environment and Development (UNCED). Rio de Janeiro, 3-14 June 1992

Ulhoi J. P., Madsen H. \& Hildebrandt S. (1996). Green new world: a corporate environmental business perspective. Scandinavian Journal of management, 12(3), 243-254

UNESCO, (2010) Education for sustainable development. March 15th 2012, from:http://www.unesco.org/en/esd/.

Wagner, J. (2006). On the economics of sustainability. Ecological economics, 57, 659-664

Watkiss, P., Downing, T. \& Handley, C. in Butterfield, R. (2005), The impacts and costs of climate change. Paper by AEA Technology Environment, Stockholm Environment Institute, Oxford. Retrieved March 15th 2012, from: http://ec.europa.eu/environment/climat/pdf/final_report2.pdf . 
Watkiss, P., Forster, D., Hunt, A. \& Smith, A. in Taylor, T. (2004), A Comparison of EU Air Pollution Policies and Legislation with Other Countries. Review of the Implications for the Competitiveness of European Industry Report for DG Enterprise. Retrieved March 15th 2012,from: http://europa.eu.int/comm/enterprise/environment/ reports_studies/reports/study1.pdf .

Yale Center for Environmental Law and Policy, (2010). University Center for International Earth Science Information Network, 2010 Environmental Performance Index - Summary for policy makers 